\title{
Protocolo y TIC: Twitter como herramienta docente Protocol and ICT: Twitter as a learning tool
}

\author{
Daniel Delmás Martín ${ }^{1}$ \\ Universitat Jaume I de Castellón \\ danieldelmasmartin@gmail.com
}

Recepción:18/06/2019 Revisión: 07/11/2019 Aceptación: 03/12/2019 Publicación: 10/11/2019

\section{Resumen}

La docencia en el s. XXI va a cambiar radicalmente. A finales del siglo pasado, con el nacimiento de internet, surgen las Tecnologías de la Información y la Comunicación (TIC) que cambian completamente la vida de las personas. Dichas tecnologías han de entrar en las aulas. Este trabajo es fruto del esfuerzo por introducir las TIC en las aulas y ayudar a los alumnos en la creación de sus Entornos Personales de Aprendizaje (PLE), con el objetivo de mejorar el proceso de enseñanza-aprendizaje para los estudiantes de protocolo.

Los pasados enero-marzo de 2018 en la clase de protocolo y organización de eventos de la Universitat Jaume I de Castellón, se convirtió la red social Twitter en una herramienta docente con el fin mejorar el aprendizaje de los alumnos de los conceptos de esta materia. Este trabajo presenta el método empleado y los resultados obtenidos.

Palabras claves: protocolo, enseñanza, Twitter, TIC, proceso de enseñanza-aprendizaje, PLE

\section{Abstract}

Teaching in the 21th century is going to change radically. At the end of last century, with the Internet's birth, Information and Communication Technologies (ICT) arise to change people's lives. These technologies must enter the classrooms. This paper is the outcome of the effort to introduce ICT in the classroom and to help the students to create their own Personal Learning Environment (PLE) to improve their understanding and learning of protocol concepts.

1 Licenciado en Publicidad y RRPP y especialista en eventos y protocolo. Más información curricular en: https://www.linkedin.com/in/danieldelmas y en www.danieldelmas.com 
Last January-March 2018 in the events organizing and protocol subject at Jaume's I University in Castellón, we converted the social media Twitter into teaching material in order to improve the learning process of the students in this theme. This paper presents the method and the results used.

Keywords: protocol, teaching, Twitter, ICT, teaching-learning process, PLE

\section{Sumario}

1. Introducción

2. Marco teórico

3. Desarrollo

4. Resultados

5. Conclusiones

6. Bibliografía

\section{INTRODUCCIÓN}

Con la llegada de internet a nuestra civilización hemos entrado en la denominada era del conocimiento digital. Cientos de miles de millones de datos en el ciberespacio los permiten aprenden sobre prácticamente, cualquier cosa. Alrededor del fenómeno " $w w w$ " han surgido toda una serie de tecnologías de la información y la comunicación (TIC) que han hecho cambiar nuestras vidas por completo. Pero lo que llega al ciudadano de a pie rápido, tarda más en llegar al resto de los espacios sociales, como es el caso concreto de las aulas.

Hoy en día, son muchos los esfuerzos que se hacen desde la administración por introducir las TIC en las clases, pero las cuestiones económicas y la resistencia de parte del profesorado esta dificultando su implantación. Hoy en día ya no se pone en cuestión que la clase magistral a la que se ha tenido acostumbrado a los alumnos ya no tienen ningún sentido. Tampoco se pone en cuestión que no usar las TIC en las aulas en un error. Qué sentido tiene ignorar aquello que los alumnos usan en su vida diaria, y que, además, tendrán que usar posteriormente en su vida profesional.

Pero la implantación de las TIC en las aulas, de por si no significa una mejora para docentes y discentes, no sirve de nada sino se da un segundo factor determinante: el cambio de rol de profesor y alumno (García González y García Ruíz, 2012). Los estudiantes tienen que tomar un papel más activo en su aprendizaje. No pueden continuar siendo meros oyentes de un monólogo impartido por un profesor y que, posteriormente, han de "vomitar" en un examen. Eso no supone aprendizaje. Y los docentes tiene que dejar de tratar a los estudiantes como si fueran una cuarta pared con la que no se interactúa. Los nuevos roles implican un profesorado que se ha convertirdo en un guía o asesor pedagógico. Su papel es 
el de guiar al alumno para que adquiera los conocimientos necesarios para desarrollarse en su vida personal y profesional. El alumno necesita tomar un papel activo en su proceso de aprendizaje. Necesita experimentar un aprendizaje por el que el profesor le ha de guiar.

\section{MARCO TEÓRICO}

Las bases sobre las que hemos construido esta investigación han sido fundamentalmente dos: el protocolo y los entornos personales de aprendizaje (PLE).

\subsection{Protocolo}

El protocolo es tan antiguo como lo es la sociedad humana. Desde el momento en el que el ser humano convive en grupos, se hacen necesarias unas reglas que garanticen la convivencia pacífica entre todos sus miembros. Si por algo se ha caracterizado el ser humano a lo de la historia, es por no tener una naturaleza anárquica. Incluso hoy en día, cuando se estudian tribus que no han tenido nunca contacto con otros grupos sociales, se puede ver cómo existen unas normas para garantizar la cohabitación. Pero a pesar de la antigüedad e importancia de esta materia, muy pocas son las investigaciones que se tienen al respecto.

Orozco López (2016) sostiene que, para entender el protocolo y conocer sus orígenes, nos hemos de remontar al momento en el que el ser humano decide vivir en sociedad, y por lo tanto, necesita organizar las relaciones entre los distintos individuos que la integran para evitar conflictos. En una sociedad gregaria y que necesita distribuir espacios y recursos, el ser humano debía, en algún momento, empezar a establecer normas que determinaran quiénes ocupaban los lugares más seguros o quiénes obtenían la comida más nutritiva, en detrimento de aquellos que eran obligados a quedarse en las zonas menos seguras y a consumir lo que los otros no querían. En palabras de Orozco López (2016) "las sociedades necesitan el protocolo, que coloca a cada cual en el lugar que le corresponde y premia las conductas valiosas de acuerdo con una escala de valores que cada sociedad y cultura ha elaborado, según sus necesidades" (p.7).

El primer texto sobre protocolo del que tenemos constancia es El Código de Hammurabi. Data del año 1750 a.C. aproximadamente y es un bloque de basalto tallado de unos $2,50 \mathrm{~m}$. de altura por $1,90 \mathrm{~m}$. de base. Fue escrito en lengua Acadio y consiste en un conjunto de leyes hechas para regular la vida cotidiana del primer Imperio Babilónico y nos interesa en esta investigación por los tres escritos relacionados con el protocolo. De todas sus indicaciones, hay dos que podríamos aplicar a la actualidad en cualquier manual de protocolo: "traten con máximo respeto y cortesía a todos los ciudadanos del reino, cualquiera que sea su nivel social" y "pongan el mayor cuidado en realizar bien y de un modo justo las ceremonias del reino, porque esto contribuye a la felicidad, prosperidad y paz de todos los súbditos". El código de Hammurabi, además, establecía que el encargado de 
garantizar que se cumplieran todas las leyes referentes al protocolo era el Sumo Sacerdote, que hoy en día equivaldría al Jefe de Protocolo de cualquier empresa o institución.

Por tanto, el protocolo es una disciplina inherente al ser humano, puesto que no está en su naturaleza vivir anárquicamente, y contribuye a generar una convivencia social pacífica. Pero, además, construye, genera y describe las estructuras sobre las cuales se vive, determinando un orden para esa convivencia positiva de la que hablábamos. Este último aspecto, lo podemos ver claramente en el Real Decreto 2099/83 que rige el orden de precedencias en los actos organizados por las instituciones españolas. Si lo leemos con detenimiento, será fácil poder describir cuáles son las principales estructuras con las que cuenta nuestro país (España).

Una vez hemos analizado el origen del protocolo, y cuál es su función principal en la sociedad, debemos analizar cuáles son sus fuentes. A este respecto hay dos autores a los que nos gustaría citar. Por un lado Sánchez González (2011) y por el otro, Barquero Cabrero, Ramos Fernández, y Medina Elizondo (2013). De acuerdo con ellos podemos afirmar que son dos:

Por un lado, las leyes. Generadas por los gobiernos para su aplicación en los actos de carácter oficial, y que nos permiten la regulación en los mismos, como por ejemplo la ordenación de los cargos institucionales en los eventos.

La segunda fuente, son los usos y costumbres sociales. Estos corresponden a aquellas reglas que decíamos al principio, que se generan para convivir socialmente, y que todos han de conocer. No están reguladas por ley, pero se siguen, puesto que es lo que se exige a todos los miembros de una determinada comunidad para ser aceptados en el misma. Se trata de un acuerdo tácito.

Fuente Lafuente (2010) califica el protocolo como necesario en todos los sectores de la sociedad actual: el mundo de la empresa, del deporte, la cultura... Este mismo autor hace una reflexión sobre el estado actual del protocolo, enmarcándolo en una crisis conceptual. Esta ciencia se encuentra en un momento de cambios. En el s. XX ha sufrido un cambio cualitativo importante, pasando de ser una herramienta tradicionalmente al servicio de las instituciones públicas tradicionalmente, para dar el salto al mundo de la empresa privada. Esta ha adoptado las formas que le son propias a las instituciones, para convertirlas en suyas en aras de generar un discurso para sus públicos.

Finalmente, terminamos este marco teórico ofreciendo una definición actual del concepto protocolo de Delmás Martín y Gómez Hernando (2019):

El protocolo es una disciplina científica transversal que define las estructuras sociales y las normas generadas por uso, costumbre, tradición o legislación de las que se dota una sociedad para garantizar y facilitar la convivencia en armonía de todos sus miembros. Como herramienta de comunicación que se aplica a todos 
los ámbitos sociales, el protocolo toma especial relevancia en la organización de actos, tanto públicos como privados, donde proporciona técnicas que permiten hacer tangible lo intangible. (p.18)

\subsection{Entornos personales de aprendizaje (PLE)}

Los denominados PLE son un elemento determinante en ese cambio de roles en el docente y los discentes del que hablábamos anteriormente. Martínez Gimeno y Torres Barzabal (2013) lo definen como:

Un PLE se basa en la utilización de herramientas de la Web 2.0 y las redes sociales, incorporándolas en el ámbito del aprendizaje, posibilitando que las personas puedan desenvolverse en dicha plataforma virtual para adquirir un aprendizaje eficaz y autónomo. (p.6)

Tomando como punto de partida este nuevo paradigma docente, debemos de dejar de preguntarnos si usar o no las TIC en el aula. La respuesta es sí, de forma rotunda. Hay otros muchos estudios que así lo prueban. Hoy en día, ya no tiene ningún sentido el negarle la entrada a las aulas a unas herramientas que los alumnos usan en su día a día y que van a formar parte de su vida personal y profesional en el futuro. Bajo esta visión de la realidad estudiantil, el PLE es una forma de guiarles en la formación de una estructura de TIC que les permita utilizar todas esas herramientas para crear un espacio de aprendizaje autónomo. No solo para la época estudiantil, sino para el futuro cuando se encuentren ejerciendo. En definitiva, debemos de enseñarles a usar esas aplicaciones de una forma que les lleve a darse cuenta que son algo más que formas de entretenimiento. Porque en palabras de Martínez Gimeno y Torres Barzabal (2013) "este modelo pone el acento en el estudiante y en las decisiones que éste adopta para personalizar y autorregular su aprendizaje, y por tanto en el papel que juega para la determinación de su propio proceso de aprendizaje" (p.6).

Adell y Castañeda (2010) trabajan con una idea similar de PLE, considerándola como "el conjunto de herramientas, fuentes de información, conexiones y actividades que cada persona utiliza de forma asidua para aprender" (p.7). Estos autores van un poco más allá que los anteriores, en tanto en cuanto, que consideran internet como un ente vivo donde no solo podemos encontrar millones de datos de información, sino que son un modo de conexión con otras personas, y, por lo tanto, la forma en la que se produce aprendizaje. Afirman que, cuando acudimos a la red a por información se produce una reelaboración y reconstrucción de la misma, una fase de reflexión y reconstrucción sobre dicha información que llevan al aprendizaje. Por ello, según Adell y Castañeda (2010):

Un PLE se configuraría alrededor de las herramientas y servicios que nos permiten el acceso y la relación con la información (acceso y actividad) y con 
otras personas, en concreto las herramientas "sociales" de la Web 2.0, y de las estrategias con que configuramos el uso de las mismas. (p7).

Finalmente, Adell y Castañeda (2010) terminan hablando de la configuración básica de los elementos que componen el PLE. Para ellos son tres elementos. El primer son las herramientas y estrategias de lectura, es decir, las fuentes de información a las que accedemos. El segundo, las denominan herramientas y estrategias de reflexión. Hace referencia a los entornos donde transformamos la información: donde escribimos, comentamos, publicamos, etc. Finalmente, hablan de un tercer elemento denominado herramientas y estrategias de relación, y que supone el espacio donde nos relacionamos con otras personas con las que aprendo o de las que aprendo.

\section{DESSARROLLO}

El trabajo de campo de esta investigación se llevó a cabo de enero a marzo de 2018 en las aulas de la Universitat Jaume I de Castellón. Los alumnos de la asignatura de Protocolo y Organización de eventos realizaron un ejercicio donde se les proponía utilizar la red de microblogging Twitter como herramienta para crear e iniciar sus PLE.

La actividad propuesta fue para llevar a cabo fuera del aula y de forma individual, y de la cual se entregó un informe a fecha de 17 de abril de 2018. Lo único sobre esta práctica que se hizo en clase, fue comentar las dudas respecto a la misma, y aprovechar los diez primeros minutos para compartir cuál era el avance que estaban experimentando: qué perfiles habían encontrado, qué tipo de información, documentos... dependiendo de la tarea concreta a desarrollar dentro del calendario semanal establecido.

El usuario que tenían que seguir, y el cual fue la fuente de emisión de los mensajes de los docentes, fue @sdprotocolo. Y para poder aglutinar todas las aportaciones realizadas se utilizó el hashtag \#ProtocoloUJl18. En él, debían de etiquetar los artículos, vídeos, infografías, etc. para que todos los alumnos los pudieran encontrar, generando así diálogo y seguimiento de los mismos. Este fue el calendario de trabajo semanal: 


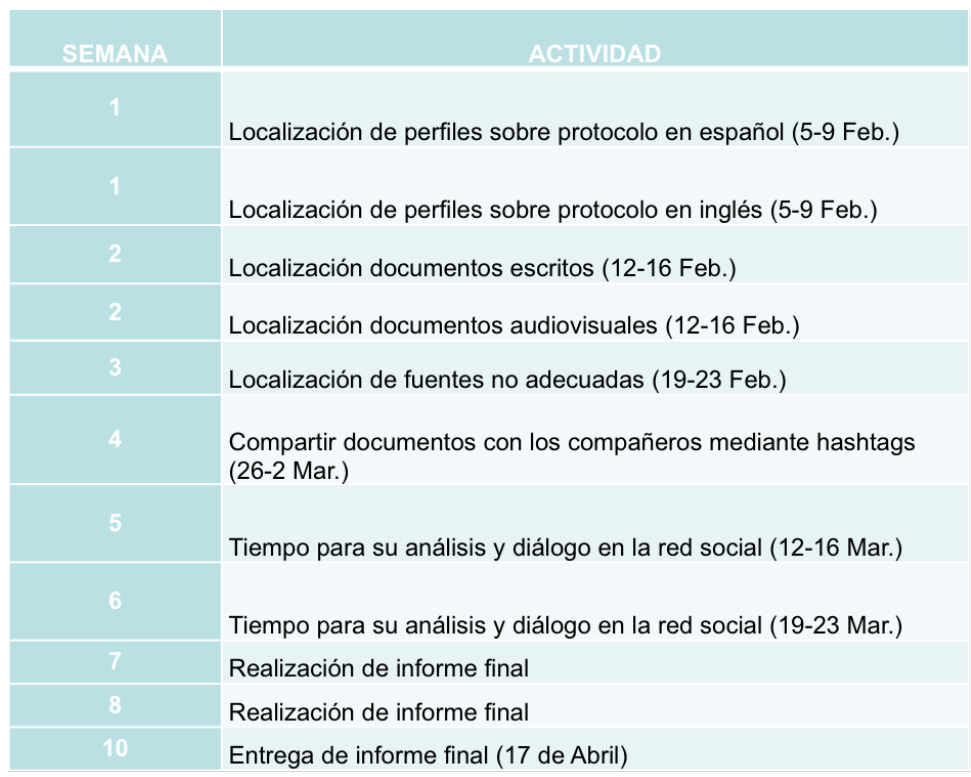

Imagen 1: Calendario actividad de Twitter

Fuente: elaboración propia

Como se puede observar se dividió en semanas, y en cada una de ellas, el objetivo de aprendizaje era diferente. La primera había que localizar perfiles que hablaran de la materia en dos idiomas, el español y el inglés. Este último es imprescindible en el mundo laboral actual, y más si hablamos de las carreras de ciencias de la información de las que provienen los estudiantes. Además de que, el protocolo es una disciplina en proceso de cambio y, dependiendo de la cultura, su perspectiva es diferente.

En la tercera semana el objetivo fue que buscaran fuentes no adecuadas. Es decir, perfiles de personas que no tienen formación en la materia y que hablan de la misma, o artículos de prensa que hablan del protocolo de forma errónea, etc.

Las semanas cinco y seis se utilizaron para darles a los alumnos elementos para reflexionar y hacer una disertación sobre temas específicos. En la semana cinco se les proporcionó el siguiente twit https://twitter.com/SdProtocolo/status/974208715397255168 donde se debía de reflexionar sobre el valor comunicativo del protocolo a partir de un artículo de un blog y una fotografía reciente. El artículo es de un profesional en ejercicio sobre nuestra disciplina, y la fotografía estaba de completa actualidad ya que era de un acto recientemente celebrado. En la semana seis se les proporcionó otro twit https://twitter.com/SdProtocolo/status/976745461993410560 en el que se les pedía hacer una reflexión a partir de la lectura de un artículo, y la visualización del vídeo del mismo sobre el llamado efecto WOW en los eventos.

Finalmente, las últimas semanas se concibieron para que hubiera tiempo de preguntar dudas o aclarar conceptos antes de la entrega final del informe. 
La forma de evaluación del ejercicio, fue un informe que constaba de tres partes: una primera, donde los alumnos debían de hacer un comentario sobre lo llevado a cabo en las semanas uno a la tres. En la segunda sección, debían de hacer un comentario de los archivos que el equipo docente les había proporcionado en las semanas cinco y seis, y finalmente, una última parte donde se recogieron dos cuestiones: la primera, su perspectiva sobre la actividad en la red social, y la segunda, qué les había aportado académicamente.

El objetivo de este esquema fue el poder valorar su efectividad y conocer si les ayudaba a generar un espacio de protocolo en sus PLE, y si realmente, al tratarse de una red social que muchos usan y les gusta, les incentiva a usarla de forma diferente mejorando su interés por la asignatura.

\section{RESULTADOS}

Por lo que a la práctica de Twitter se refiere, salvo en lo que respecta a la participación en la red social, y de lo que hablaremos más adelante, consideramos que los resultados fueron satisfactorios. De hecho, sorprendió a los propios alumnos, que mayoritariamente agradecieron y manifestaron que este ejercicio fue muy beneficioso para ellos en el apartado de opinión personal del informe entregado.

La siguiente imagen pertenece a un análisis del hashtag en un periodo de tiempo de diez días durante el pasado marzo 2018.

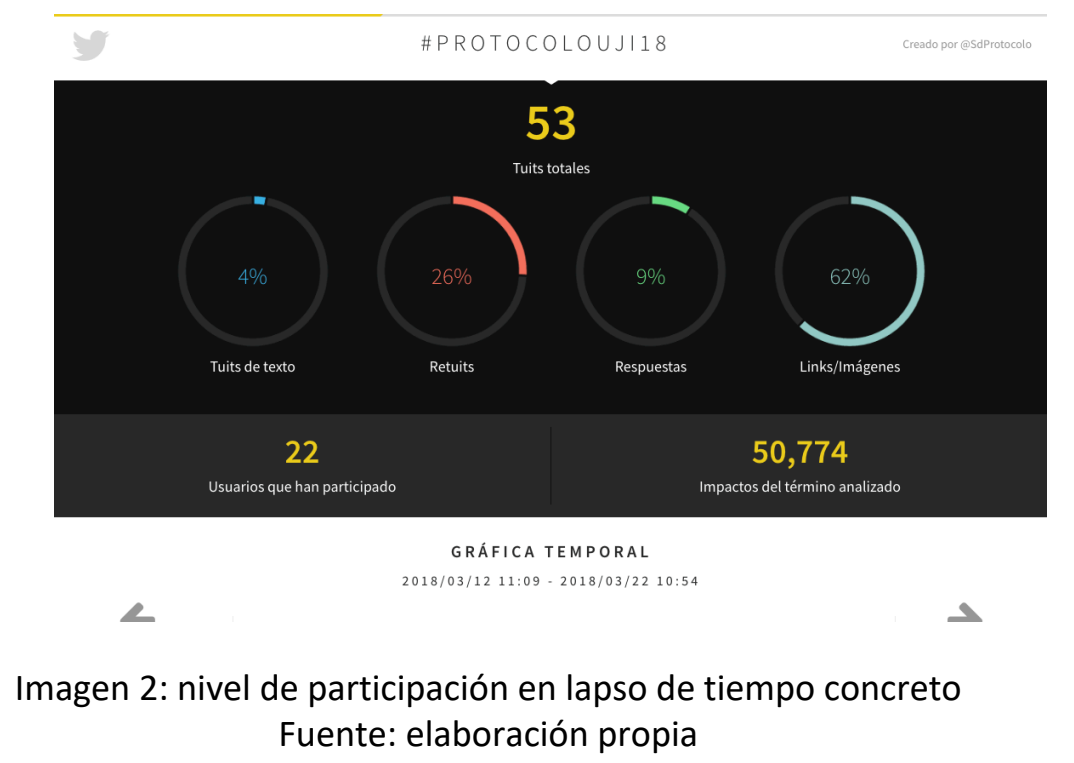

De las cifras de la imagen podemos obtener datos interesantes. Por un lado, que estuvieron activos durante ese lapso de tiempo un total de 22 alumnos (de un total de 46 ). $Y$ que se emitieron un total de 53 twits. De ellos el $26 \%$ fueron retwiteados, y el $62 \%$ de esos twits eran links a otros contenidos, tales como webs, vídeos, artículos de blog o prensa... o 
imágenes de infografías o fotografías. El $4 \%$ de las interacciones fueron únicamente texto, y que el $9 \%$ de ellas, obtuvieron respuesta.

Desde el principio se les pidió que se participará todas las semanas, lo cual supondría un punto de la calificación final de la práctica entregada. Ese punto se obtenía con la participación hasta el $2 / 3 / 2018$. Vamos ahora a ver los datos de participación, obtenidos a partir del hashtag \#ProtocoloUJI18 y referidos al total de 46 ejercicios entregados.

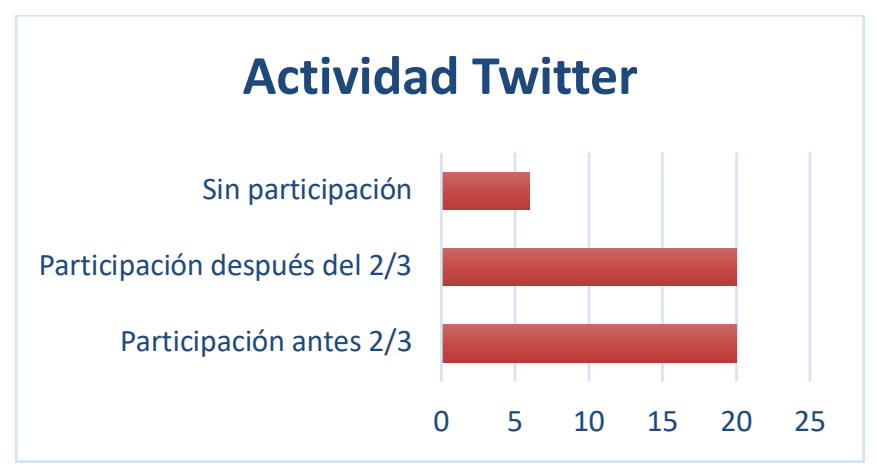

Gráfico 1: participación alumnos según calificación en informe Fuente: elaboración propia

Si analizamos los datos de participación en la red social de los alumnos del gráfico anterior, podemos ver como veinte de ellos obtuvieron un punto, puesto que su interacción en Twitter fue realizada desde el principio tal y como se les había pedido. Esto nos deja otra veintena de ellos que, empezaron a participar en la plataforma pasada la fecha de dos de marzo, por tanto, su puntuación en el informe fue de medio punto. $Y$ finalmente, tenemos un total de seis estudiantes, que entregaron el informe de la actividad, pero que no hicieron ninguna intervención en Twitter por lo que no obtuvieron puntuación alguna en este apartado.

En general, las notas obtenidas por los alumnos en la evaluación del informe final fueron muy buenas. La media de los 46 alumnos se situó en el 7,85 (sobre 10 puntos).

En lo que respecta a la propia evaluación de los alumnos a la actividad con Twitter, las opiniones fueron muy positivas. Una amplia mayoría de los alumnos afirmó que la actividad les había permitido descubrir Twitter desde una perspectiva formativa, y no solo para el ocio y tiempo libre. Del mismo modo, muchos afirmaron que el navegar por la red social y buscar perfiles que hablen sobre esta disciplina, les ha ayudado a asentar los conocimientos que tenían, a adquirir nuevos y a descubrir el mundo del protocolo y los eventos con una visión mucho más amplia. 


\section{CONCLUSIONES}

La perspectiva docente del protocolo y la organización de eventos, necesita empezar a introducir un cambio. El sistema de clase magistral no tiene sentido en la era del conocimiento digital, por tanto, se necesita empezar a caminar hacia un cambio de roles de estudiantes y profesores.

El profesor debe de asumir un rol de guía y asesor docente. Su objetivo es crear un perfil de discente en el que este tome un papel activo en su formación en busca del denominado "aprendizaje significativo".

Las TIC forman parte de la vida de los alumnos y deben de ser introducidas en el aula para que formen parte del método de aprendizaje de los discentes. El docente ha de diseñarlas como herramientas pedagógicas con el fin de que cumplan su objetivo en las aulas.

La existencia del PLE en los estudiantes es irrefutable. Es tarea de los docentes el guiarlos a través de su adecuada construcción con el fin de que les ayuden a experimentar un aprendizaje activo, así como asentar su formato para que este siga tras el periodo estudiantil.

Twitter es una plataforma perfecta para contribuir al desarrollo del PLE de los estudiantes. La forma en la que está configurada permite la búsqueda por temas y ayuda a interactuar con profesionales de la materia que aporten una visión actual sobre el protocolo.

Las TIC están teniendo una entrada lenta en las aulas fundamentalmente por dos razones: en primer lugar, que la inversión en las aulas desde la crisis de 2007 en España se ha recudido, por lo tanto, se invierte menos en tecnología para transformar las aulas. Y en segundo lugar, que los docentes necesitan invertir más tiempo con las TIC en preparar las clases, lo que se traduce en una reticencia por parte del docentes. Además, que, hay algunos profesores que se resisten a hacer el cambio por diversas razones.

\section{BIBLIOGRÁFIA}

Adell, J., y Castañeda, L. (2010). Los Entornos Personales de Aprendizaje (PLEs): una nueva manera de entender el aprendizaje. Learning, 16.

Barquero Cabrero, J. D., Ramos Fernández, F., \& Medina Elizondo, M. (2013). Protocolo y relaciones Públicas en la sociedad pluralista. Usos, normas y reglas en actos públicos y privados. (Furtwangen). Barcelona: ESERP, School of business and social sciences. Colección ciencias económicas y sociales.

Delmás Martín, D., y Gómez Hernando, M. (2019). Spoilers de Protocolo. (Editorum, Ed.) (1 Edición). Madrid: Editorum.

Fuente Lafuente, C. (2010). Protocolo Oficial (5 Edición). Ediciones Protocolo. Colección Área de Formación. 
García González, J. L., \& García Ruíz, R. (2012). Aprender entre iguales con herramientas web 2.0 y Twitter en la Universidad. Análisis de un caso. EDUTEC. Revista Electrónica de Tecnología Educativa., 1-14.

Martínez Gimeno, A., y Torres Barzabal, L. (2013). Los entornos personales de aprendizaje (PLE). Del cómo enseñar al cómo aprender. Edmetic, Revista de Educación Mediática y TIC, 39-57.

Orozco López, J. D. D. (2016). Protocolo para la organización de eventos. (I. Editorial, Ed.) $\left(1^{\mathrm{a}}\right)$. Antequera: IC Editorial.

Sánchez González, D. del M. (2011). Fundamentos del ceremonial y del protocolo. Editorial Síntesis. 